\title{
Uterine fluid accumulation and endometrial integrity in the barren mare
}

\author{
Anne-Cécile Lefranc and William R. (Twink) Allen \\ University of Cambridge, Equine Fertility Unit, Mertoun Paddocks, Woodditton Road, Newmarket, Suffolk, CB8 9BH, UK
}

\begin{abstract}
Summary
Videoendoscopic evaluation of the uterus has been well described in fertile and subfertile mares. The technique allows visualisation of the vaginal walls, the cervix, the endometrium and the utero-tubal papillae. A healthy und functional endometrium is vital throughout gestation in the mare, especially at implantation and during the long period preceding it, when the unattached embryo takes its sustenance entirely from the exocrine secretions of the endometrial glands. Hence, videoendoscopic examination of uterine integrity is a valuable adjunct to any evaluation of fertility or infertility. The method enables observation of hyperaemic inflammation or sloughing of the endometrium that cannot be detected ultrasonographically. Such endometrial damage can result in fibrotic scaring and/or intralumenal adhesions that can trap fluid in pockets and that can potentially reduce fertility. If uterine fluid accumulation in the mare can easily be diagnosed by ultrasonographic examination of the genital tract, videoendoscopic examination of the uterine lumen is the appropriate method to evaluate the severity and extent of the lesions. The aim of this paper is to describe, through four clinically relevant cases, the range of aetiologies of uterine fluid accumulation and to discuss the use of videoendoscopic examination to efficiently evaluate the extent and significance of endometrial lesions and therefore provide an accurate prognosis of future breeding potential.
\end{abstract}

Keywords: mare, uterus, endometrium, fluid, infertility, reproduction

\section{Uterine Flüssigkeitsakkumulation und endometriale Struktur bei güsten Stuten}

Die Videoendoskopie des Uterus ist eine gut beschriebene Methode bei fertilen und subfertilen Stuten. Ermöglicht wird die Visualisierung der vaginalen, zervikalen und endometrialen Oberflächen einschließlich der uterotubalen Papille. Ein gesundes und funktionsfähiges Endometrium ist eine essentielle Voraussetzung für die gesamte Trächtigkeit der Stute. Dies gilt jedoch speziell für die Zeit der Implantation und dem langen ihr vorausgehenden Intervall, in dem der noch nicht haftende Embryo ausschließlich durch die exokrinen Sekrete der endometrialen Drüsen alimentiert wird. Aus diesem Grund ist die Videoendoskopie eine wertvolle Ergänzung bei jeglicher Überprüfung bezüglich Fertilität/Subfertilität. Die Methode ermöglicht den Nachweis entzündlicher Hyperämien und Schleimhautablösungen, die mittels der Sonographie nicht erfasst werden können. Derartige endometriale Schäden können zu Narbenbildungen und/oder intraluminalen Adhäsionen mit Taschenbildungen und Flüssigkeitsansammlungen und damit zu einer reduzierten Fertilität führen. Wird ultrasonographisch eine Flüssigkeitsansammlung diagnostiziert, ist die Videoendoskopie die geeignete Methode, das Ausmaß und den Grad der Läsionen zu konkretisieren. Das Ziel der Arbeit ist, anhand von vier klinisch relevanten Fällen die Bandbreite der Ursachen von intrauterinen Flüssigkeitsansammlungen aufzuzeigen. Diskutiert wird die Nützlichkeit einer videoendoskopischen Untersuchung hinsichtlich einer effizienten Bestimmung von Ausmaß und Bedeutung endometrialenr Läsionen und damit einer präzisen Prognose bezüglich des zukünftigen Fruchtbarkeitspotentials der Stute.

Schlüsselwörter: Stute, Uterus, Endometrium, Flüssigkeit, Infertilität, Reproduktion

\section{Introduction}

Uterine fluid accumulation in the mare is easily diagnosed by ultrasonographic examination of the genital tract. The accumulated fluid appears as an anechogenic area within the uterine lumen that is more or less uniform in structure and size. Accumulated fluid is usually recognised during routine ultrasonographic breeding examinations of oestrous mares when, under the influence of follicular oestrogens, the oedematous endometrium releases a small quantity of serous-like fluid that can appear as an irregular anechogenic area in the uterine lumen and be easily expelled from the uterus by an intravenous injection of an ecbolic drug like oxytocin (Allen 1991). When the quantity of fluid exceeds $2 \mathrm{~cm}$ in width, the mare is generally considered to be "abnormally infected" and possibly to need appropriate therapy to evacuate the fluid prior to natural mating or artificial insemination. In such cases, a comprehensive gynaecological examination should be undertaken, not only to try eliminating the accumulated fluid from the uterus, but also to determine the cause of its accumulation in order to establish both a breeding prognosis and a rational course of therapy. Indeed, the integrity of the endometrium may be affected, e.g. excessive stromal and glandular fibrosis and/or lumenal adhesions and cysts that trap the fluid in pockets, in which case videoendoscopic examination of the uterine lumen is the appropriate method to evaluate the severity and extent of the lesions (Wilson 1983, Benedetto et al. 1990, Bracher and Allen 1992a, $1992 \mathrm{~b})$. The aim of this paper is to describe, through four clinically relevant cases, the range of aetiologies of uterine fluid accumulation and to discuss on complementary examinations that may improve diagnosis, therapeutics and breeding prognosis. 


\section{Case 1: Persistent moderate uterine fluid accumulation}

The first case was an active 7 year-old show jumper maiden mare included in an embryo transfer programme. Clinical examination of the reproductive tract revealed no abnormality. On vaginal examination, the cervix appeared very long and tight, even when under the influence of follicular oestrogens. Several attempts were made during the breeding season to produce embryos. In each oestrous period, the mare exhibited normal ovarian follicular growth and a slight-tomoderate accumulation of normal, darkly echonegative fluid in the uterine lumen that needed repeated administrations of oxytocin (20 I.U. i.v.) in order to expel it; ovulation appeared ultrasonographically normal. After artificial insemination (AI) with fertile frozen-thawed semen, fluid systematically accumulated in much larger quantities in the uterine lumen. This required thrice daily administration of oxytocin, together with manual dilatation of the tight cervix, during two days postovulation before total uterine clearance was achieved. No embryo was recovered during 5 flushing attempts. Cytological swabbing of the uterus did not indicate a bacterial infection and videoendoscopic examination of the lumen showed a normal healthy-looking endometrium. The mare had been kept stabled during the whole of the season but it was now agreed, with the following season, to leave her outside during the day in a small paddock next to a double fenced paddock containing an intact stallion. This change in management resulted in a marked reduction in uterine fluid accumulation during oestrus and she produced 4 viable embryos that upon transfer to synchronised recipient mares produced 4 healthy foals. That case highlights a useful breeding management method for maiden Sporthorse mares with a tight muscular cervix that traps oestrous secretions in the uterus.

\section{Case 2: Persistent severe uterine fluid accumulation}

The second case presented a 12 year-old infertile maiden Pony mare with persistent severe uterine fluid accumulation. Transrectal palpation of the reproductive tract highlighted a distended and flaccid uterine body, with a very tight and enlarged cervix. Ultrasonographic examination showed normal ovarian activity and a large amount (>5 cm depth) of large echogenically "cloudy" fluid in the uterus. Several attempts of manual dilatation of the cervix, together with repeated large volume saline uterine lavages followed by oxytocin administration did not improve the clinical status. The cervix remained very tight throughout the oestrous cycle and insertion of a finger into it highlighted its very twisted lumen. Videoendoscopic examination of the uterine lumen revealed the accumulation of a pus-like uterine fluid and showed the endometrium to be pink and inflamed over the entire uterine surface (Figure 1). An endometrial biopsy, taken to assess the microscopic appearance of the endometrium was classified as Grade III in the Kenney and Doig (1986) scale, with severe non-reversible, fibrous, degenerative changes, including "gland nest" formation throughout the section. This case emphasized the importance of complementary investigations when classical therapeutic treatment regimes have already been attempted. When the cause of fluid accumulation was elucidated (an anatomically abnormal cervix), a more rational decision could be made with regard to therapy. Videoendoscopic assessment can therefore be useful to assess endometrial integrity, as a complement to endometrial biopsy.

These two first cases described free fluid accumulation in the uteri of mares, with different degrees of severity. In both instances, a complete examination of the reproductive tract was necessary, with emphasis on cervical integrity. Uterine fluid can also become trapped in fibrous cavities, as illustrated by the next two cases.

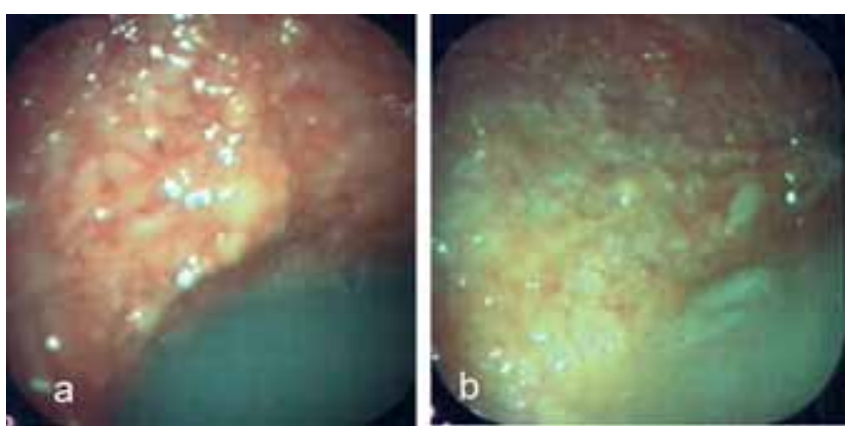

Fig 1 Videoendoscopic appearance of a) an intrauterine accumulation of pus; b) a badly fibrosed endometrium.

Videoendoskopische Aufnahme von a) einer intrauterinen Eiteransammlung, b) einem Endometrium mit ausgedehnten Fibrosen.

\section{Case 3: Encapsulated uterine fluid due to severe adhe- sions}

This third case was a 5 year-old maiden mare that had failed to conceive to mating in the two previous breeding seasons. No abnormality of the reproductive tract could be detected by rectal palpation but small pockets of encapsulated uterine fluid were seen ultrasonographically in both uterine horns. Unlike free uterine fluid, when the edges of the fluid are irregular and the shape and general appearance of the accumulation changes between two serial ultrasonography examinations, encapsulated fluid has a more regular outline which remains unchanged (Figure 2).
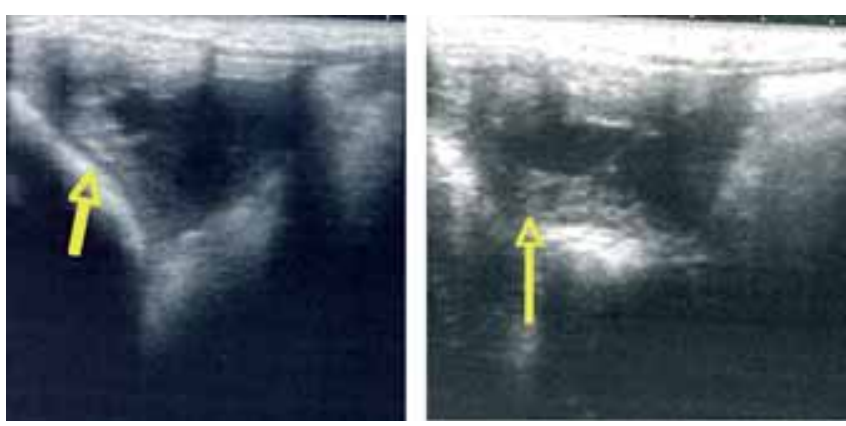

Fig 2 Ultrasonographic image of encapsulated uterine fluid accumulation (arrows).

Ultrasonographisches Bild eingeschlossener Flüssigkeitsansammlungen (Pfeile).

In the present mare, there was no apparent response to intravenous oxytocin injections and videoendoscopic examination of the uterus revealed severe transluminal sheet and cord-like fibrous adhesions throughout the entire uterus (Figure 3). Pus and fluid was trapped in various pockets and entry into both uterine horns was completely excluded. These terrible fibrotic lesions were the consequence of an in utero infusion of an irritant liquid, possibly iodine, and they 
completely precluded any chance of conception. An attempt was made to gain entry to the lumenae of the uterine horns by means of videoendoscopic NdYAG laser ablations of the adhesions but the intervention was ceased when the severity of the condition and the hopeless fertility prognosis was realised. The case illustrated starkly the great danger of infusing irritant solutions into the mare's uterus. The equine endometrium is very fragile and can react severely to such untoward irritation.
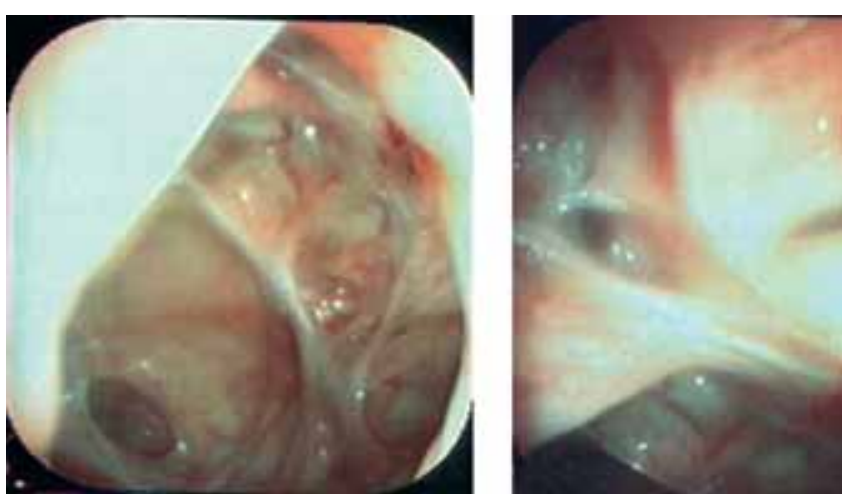

Fig 3 Videoendoscopic view of severe uterine adhesions. Endoskopische Aufnahme schwerer uteriner Adhäsionen.

\section{Case 4: Encapsulated uterine fluid accumulation follo- wing caesarean section}

The fourth case was an 8 year-old mare referred with a similar history of infertility and ultrasonographic images of pockets of trapped fluid. On rectal palpation, the uterus felt turgid but otherwise normal in size and shape. No extrauterine adhesions were noted and the uterus was freely mobile in the abdominal cavity. Ultrasonographical images of non-echogenic fluid trapped behind an echogenic fibrous band were visible in one uterine horn and the ova-

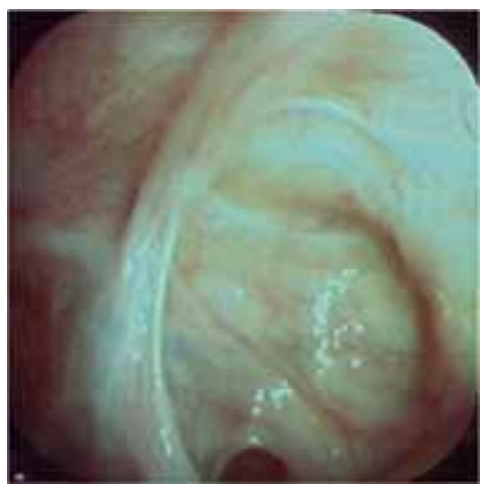

Fig 4 Videoendoscopic image of a translumenal uterine adhesion completely occluding the entrance to the uterine horn.

Videoskopisches Bild einer transluminalen uterinen Adhäsion, die die Einmündung in das Uterushorn vollständig verschließt.

ries appeared normal. Videoendoscopic examination revealed 2 or 3 translumenal sheet-like adhesions that had developed following a caesarian section operation performed 3 years previously. Here again, the severity of these adhesions was such that the entrance to a uterine horn was completely occluded (Figure 4). They were laser ablated to reveal further sheet-like bands throughout the remainder of the uterine horn. Further local laser treatment was imprac- tical and the decision was made to perform a hemihysterectomy to remove the badly affected uterine horn and to leave the ovaries and remainder of the uterus to produce viable, non-infected embryos for transfer to recipient mares (Figure 5). Thus, in this case, videoendoscopic visualisation of the endometrium allowed delimitation of intact, normal endometrium in one uterine horn and removal of the severely damaged and infected endometrium in the other horn.

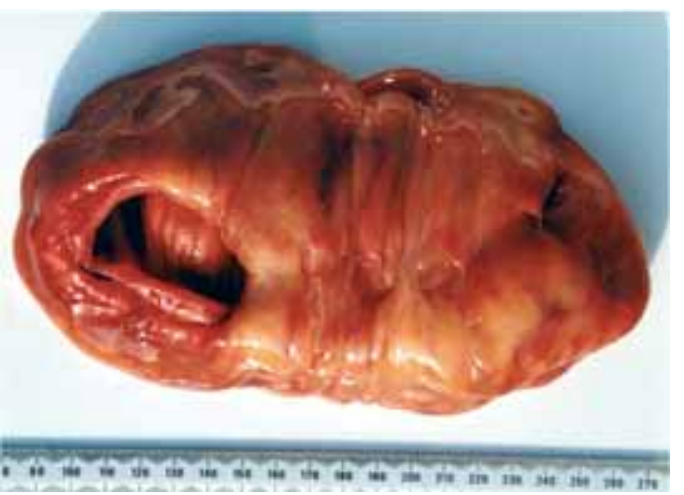

Fig 5 Uterine horn showing extensive fibrotic adhesions following surgical removal.

Uterushorn nach chirurgischer Entnahme: extensive fibrotische Adhäsionen.

Ultrasonographic examination of the uterus of the two infertile mares described in Cases 3 and 4 revealed pockets of encapsulated uterine fluid with a regular outline. This contrasted with the irregular shape of the free fluid accumulated in the uteri of the previous two mares during oestrus. In both cases, videoendoscopic examination revealed severe translumenal sheet and cord-like fibrous adhesions that were trapping pus in pocket-like cavities and were totally occluding entry into one or both uterine horns. In both mares, videoendoscopic examinations showed that the degree of adhesion formation and general fibrosis was so great that either retirement from breeding or hemihysterectomy followed by embryo transfer were the only options.

\section{Conclusion}

Uterine fluid accumulation can often be visualised during routine ultrasonographic examinations of oestrous mares, but its presence in exaggerated amounts suggests susceptibility of the mare to uterine infection and it should be eliminated. Fluid can either be free flowing in the uterine lumen, as shown in Cases 1 and 2, or trapped and encapsulated by fibrous scar tissue, as shown in Cases 3 and 4 . Ultrasonographic examinations normally allow distinction between the two and give a good lead on treatment and fertility prognosis. When non-physiological excess uterine fluid is found, a cytology smear and swab should permit identification of any bacteria involved and elimination of venereal diseases. An initial intravenous treatment with oxytocin should help clear the fluid by inducing powerful myometrial contractions and large volume uterine lavage combined with oxytocin administrations may also be required. Complementary examinations, such as videoendoscopy, and/or endometrial biopsy, should be considered both to visualise endometrial integrity and assist any decision on treatment. Moreover, endometrial inflammation 
in the mare can result in fibrous scaring and intralumenal adhesions, with the latter trapping uterine fluid and promoting infection. Videoendoscopic examination of the interior of the uterus is the only valid way to fully evaluate the extent and significance of any intrauterine lesions and therefore provide an accurate prognosis of future breeding potential. If endometrial damage is restricted to one half of the uterus, hemihysterectomy can to be a solution to allow use of the ovaries and remainder of the uterus to produce viable embryos for transfer to recipient mares.

\section{References}

Allen W. E. (1991) Investigations into the use of exogenous oxytocin for promoting uterine drainage in mares susceptible to endometritis. Vet. Rec. 128, 593-594

Bracher V. and Allen W. R. (1992a) Videoendoscopy evaluation of the mare's uterus: I. Findings in normal fertile mares. Equine vet. J. $24,274-278$
Bracher V., Mathias S. and Allen W. R. (1992b) Videoendoscopy evaluation of the mare's uterus: II. Findings in subfertile mares. Equine vet J. 24, 279-284

Benedetto V., Zona. G. and Sobbrio G. (1990) The diagnostic value of hysteroscopy in infertility investigations. Human Reprod. 5. Suppl. abstr. 241, 75

Kenney R. M. and Doig P. A. (1986) Equine endometrial biopsy. In: Current Therapy in Theriogenology. 2nd édition, Ed. D.A. Morrow, W.B. Saunders, Philadelphia, 723-729

Wilson G. L. (1983) Equine hysteroscopy: A window to the internal reproductive tract. Vet. Med. 78, 1455-1466

\section{Anne-Cécile Lefranc}

Ecole Nationale Vétérinaire de Lyon

Biologie et Pathologie de la Reproduction

1 avenue Bourgelat

69280 Marcy l'Etoile

France

ac.lefranc@vet-lyon.fr
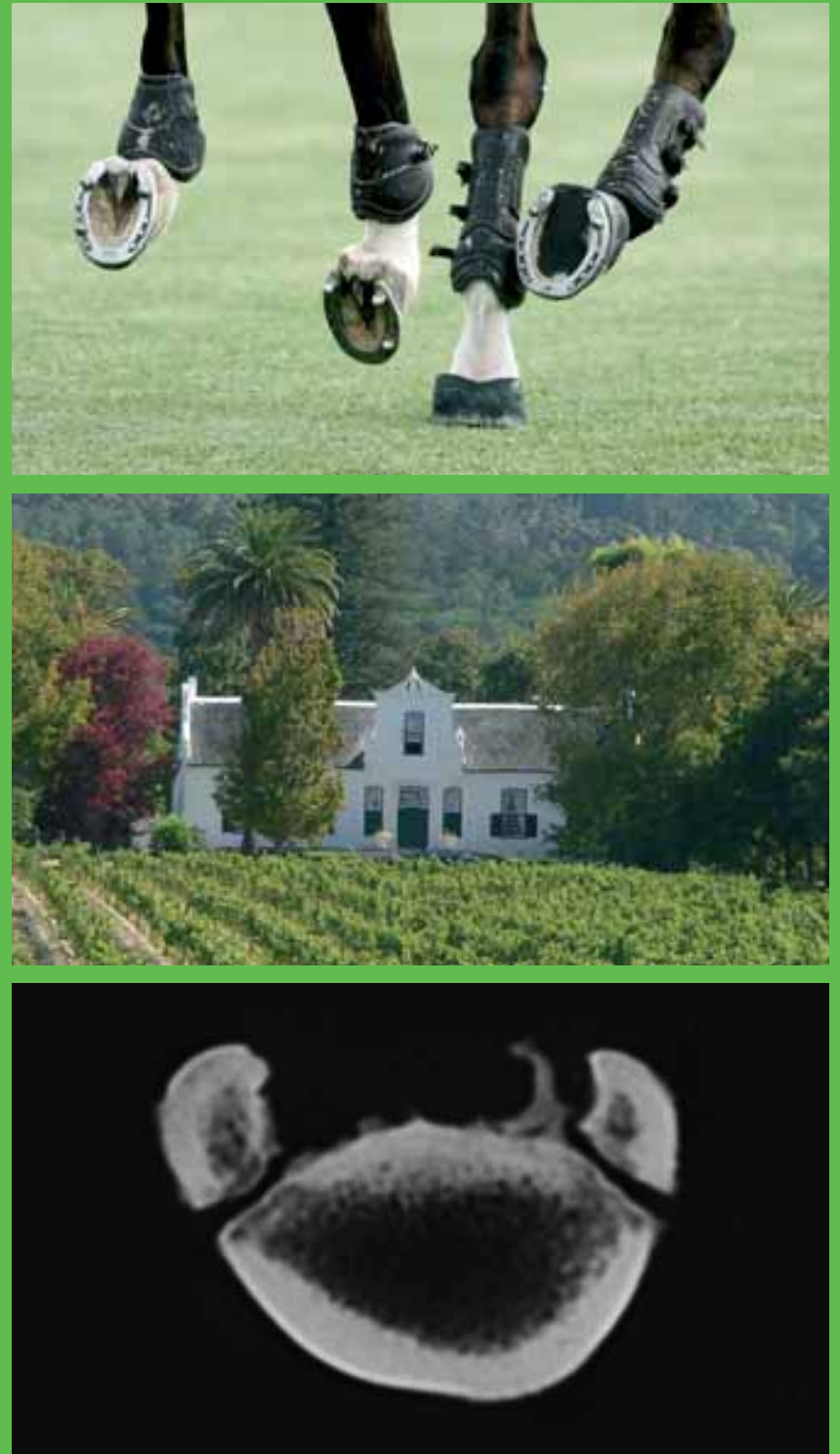

\section{EQUINE}

VETERINARY CAPE

Seminarwoche 2008

15.-19. März

Kapstadt

Progress in Equine Orthopedics

5 Tage am Runden Tisch mi†

$$
\begin{aligned}
& \text { Andrew Dart, AUS } \\
& \text { Christina Dart, AUS } \\
& \text { Roy Gottschalk, RSA } \\
& \text { Astrid Rijkenhuizen, NL } \\
& \text { Susan Stover, USA }
\end{aligned}
$$

Sybrand van den Berg, RSA

Mary Beth Whitcomb, USA

Abendprogramm

www.vetcape.com 